\title{
Factors Affecting Mortality and Length of Stay Following Clostridium Difficile Associated Diarrhoea: Validating A Consistent Scoring System
}

\author{
Wynell-Mayow W, Cash D, Muniz-Tererra G, Gkrania-Klotsas E and Khanduja V*
}

Addenbrooke's - Cambridge University Hospitals NHS Foundation Trust, Cambridge, CB20QQ, United Kingdom

*Corresponding author: Vikas Khanduja, Department of Orthopaedics, Addenbrooke's - Cambridge University Hospitals NHS Foundation Trust, Cambridge, CB20QQ, United Kingdom, E-mail: vk279@cam.ac.uk

Received Date: May 11, 2017; Accepted Date: May 31, 2017; Published Date: June 05, 2017

Copyright: (c) 2017 Khanduja V, et al. This is an open-access article distributed under the terms of the Creative Commons Attribution License, which permits unrestricted use, distribution, and reproduction in any medium, provided the original author and source are credited.

Citation: Wynell-Mayow W, Cash D, Muniz-Tererra G, et al. Factors Affecting Mortality and Length of Stay Following Clostridium Difficile Associated Diarrhoea: Validating A Consistent Scoring System. Arch Clin Microbiol. 2017, 8: 3.

\section{Abstract}

\section{Background}

Clostridium difficile associated diarrhoea (CDAD) is a severe threat, occurring with increasing frequency, severity and mortality. There is currently no consensus on a validated scoring system of CDAD severity, to guide the decisions of clinicians, and bodies such as Public Health England. Validation of these scoring systems could help improve patient outcomes and allow accurate resource allocation, particularly in light of novel, costly therapies.

\section{Patients and methods}

This study is a prospective cohort analysis of 329 toxin assay positive CDAD episodes in a tertiary University hospital in the UK. Demographic parameters recorded included age, sex and comorbidities, whilst blood markers included haemoglobin, white cell count, creatinine and albumin. These along with other variables were compared with the 30-day all cause mortality and length of infection in this cohort of patients.

\section{Results}

Sixty four percent of the patients were aged over 70, $61 \%$ were female, and CDAD was more common in patients with multiple co-morbidities. Our data showed that $96 \%$ of the cases were hospital acquired, of which $90 \%$ occurred on the medical wards. We found that older age, higher white blood cell count (WBC), higher creatinine and lower albumin were significant positive predictors of mortality, whilst haemoglobin, and Charlson co-morbidity index were non-predictive. We also found that amongst these parameters, old age and a higher white blood cell count were the only parameters associated with length of infection.

\section{Conclusion}

Our data supports the results of a previous systematic review and contradicts many currently proposed risk stratification systems, including the guidance by Public Health England. We anticipate that our results will help direct the medical community to a consensus on a risk stratification system that uses albumin, creatinine, age and WBC as markers for CDAD mortality.

Keywords: Clostridium difficile; Scoring system; Mortality; Severity; Validation

\section{List of abbreviations}

CDAD: Clostridium Difficile Associated Diarhoea; $\mathrm{Hb}$ : Haemoglobin; LOI: Length of Infection; NIHR: National Institute for Health Research; OR: Odds Ratio; SE: Standard Error; WBC: White Blood Cell Count

\section{Background}

Since it was first isolated eighty years ago as a commensal in the intestinal flora of neonates [1] Clostridium Difficile has become recognised as a major human pathogen [2] with an inpatient mortality rate three times higher than for age and comorbidity matched controls [3]. As a spore-forming Grampositive anaerobic bacillus, the symptoms of $C$. Difficile associated diarrhoea (CDAD) can range in severity from mild and self-limiting to fulminant infection resulting in a toxic megacolon and pseudomembranous colitis, carrying a mortality rate of $35 \%$ [4].

Injudicious antibiotic administration, particularly polypharmacy and the continued use of non $C$. difficile antibiotics after diagnosis of CDAD have been clearly documented as major risk factors for both developing CDAD and for subsequent relapses $[5,6]$ with the majority of antibiotics implicated as a risk factor for infection $[7,8]$ This has led to the guidance of metronidazole or vancomycin as the standard treatment of choice for $\operatorname{CDAD}[9,10]$ with some authors 
suggesting a pulsed or tapering dosage to reduce the risk of relapse [11].

However, despite the prescribing guidance, the incidence of CDAD has risen steadily over the past two decades [12] with Public Health England recording a 50-fold increase in the rate of CDAD since the 1990s, peaking at 50,000 cases in 2007 [13]. Furthermore, since 2001, the severity of infection has steadily increased, as has the incidence of the highly virulent $C$. difficile ribotype 027 [14-17] with a 2010 review of 10,975 CDAD cases demonstrating a doubling of the mortality rate (4\% to $8 \%$ ) since 2000 [18] This has led to a renewed interest in the use of innovative treatments for CDAD such as antibodies, probiotics and vaccines [19-22] Due to the large costs involved with these novel treatments and the significant mortality rate associated with severe CDAD, it has become increasingly important to prospectively identify those patients who are most at risk of developing CDAD in order to allocate resources appropriately.

The latest UK guidance on the treatment of CDAD is based on risk stratification into mild, moderate, severe and life threatening (fulminant) infection $[13,19]$. This stratification aims to produce protocol driven assistance for deciding appropriate pharmacological treatment. However, despite the recognised need to identify those patients most at risk of mortality, there is currently no consensus in the medical literature on a validated scoring system, which can objectively and reproducibly assess the severity of CDAD [22-25].

This article aims to build on the work of previous studies in further assessing the positive predictors of mortality whilst discussing those parameters, which have no value as risk markers. We also assess the factors, which play a role in increased length of infection (LOI) and therefore hospital stay and cost. The findings are finally contrasted with current public health guidance regarding risk stratification with a view to discussing improvements to the risk assessment process.

\section{Patients and methods}

Patients of all ages, who were diagnosed to have a $C$. difficile toxin positive stool culture in our tertiary University hospital were entered onto a central database with demographic, clinical and pathological data recorded for the duration of the infective episode. A prospective cohort analysis was conducted on these recorded cases with 341 infective episodes identified over the three-year period between 2009 and 2012. Patients readmitted to the infectious disease ward for suspected repeat CDAD in a single hospital visit, without a record of having cleared the previous infection were considered a single case whereas patients readmitted with a record of having cleared the initial infection and with a new positive toxin assay were considered as separate cases. Following these inclusion criteria, the study included 329 unique cases of CDAD.

Demographic parameters included age and sex of the patient whilst blood markers included haemoglobin, white cell count, creatinine and albumin. The most recent blood results after the diagnosis of infection were utilised with all samples taken within 72 hours of a positive stool culture. A senior member of the infectious diseases team clinically judged the clearance of infection, with toxin-clear stool samples not routinely requested.

Mortality was defined as 30-day all-cause mortality, in accordance with the definition identified in the systematic review by Bloomfield et al. [23]. Length of infection (LOI) was defined as the length of time from the positive stool $C$. difficile toxin assay to the date of clinical resolution.

The Charlson comorbidity Index was used as a measure of comorbid illness which was calculated using the patient's age and co-morbidity at the time of admission [26,27]. Charlson index was treated as a continuous variable for the purpose of statistical validation in accordance with study protocols identified in the systematic review by Bloomfield et al. [23].

Univariate associations of mortality were conducted using a two-tailed t-test, looking at differences in mean age, white cell count, creatinine, albumin, haemoglobin and the Charlson index, between survivors and non-survivors. Independence of renal disease and mortality was tested using Pearson's chi-squared test. A significance level of $\alpha=0.05$ was considered in all tests performed. Multivariate analysis using logistic regression was used to test the single variable association of age, creatinine, albumin, haemoglobin, renal disease, or Charlson index, with mortality.

Linear regression analysis was used to examine the association between length of infection and age, creatinine, haemoglobin, and the Charlson index. To ensure fulfilment of statistical assumptions, length of infection was logarithm transformed before analyses. Hence results are presented for the transformed length of infection.

\section{Results}

In this prospective cohort analysis of 329 cases of toxin assay confirmed CDAD, patient age ranged from 2-105 years, with CDAD occurring more frequently in those with advancing age (64\% $\geq 70$ years) (Figure 1 ). CDAD was also observed to affect females more frequently than males making up $61 \%$ of the cases $(F=201, M=128)$ (Figure 1). Of the 194 cases where place of CDAD acquisition was recorded, 96\% were hospital acquired, and $90 \%$ were from a medical ward - the most common specialty of which was geriatrics (Table 1). CDAD commonly affected patients with multiple comorbidities, with an average Charlson Index score of 4.92 within the cohort (Table 1).

Statistically significant differences were found between survivors and deceased patients by age, $(p=0.0001)$, WBC $(p=0.012)$, creatinine levels $(p=0.015)$, and albumin levels $(p<0.01)$; but not by sex $(p=0.317)$, place of acquisition, Charlson index $(p=0.165)$, or $\mathrm{Hb} \quad(p=0.581)$ (Table 1$)$. The logistic regression analysis identified albumin concentration as inversely associated with mortality when taken in isolation. In fact, per unit increase in albumin, the odds of death decreased, Odds ratio $(\mathrm{OR})=0.85$ (Standard Error $(\mathrm{SE})=0.0387, \mathrm{P}<0.0001$ ). White cell count achieved borderline significance $(p=0.052)$, however none of the other factors evaluated using this method were found to be independently associated with mortality. 
Results from the regression analyses performed demonstrated that, age $(p<0.0001)$ and white cell count $(p=0.011)$ were associated with longer length of infection, but no evidence was found of an association between length of infection and creatinine, albumin, haemoglobin, Charlson index or renal disease (Table 1). In fact, per extra year of age, the logged length of infection increased by 0.020 days ( $\mathrm{SE}=0.005$ ) whilst per $109 / \mathrm{L}$ increase in white cell count, the logged length of infection increased by 0.037 days $(\mathrm{SE}=0.014)$.

Table 1: Demographic, Clinical and Univariate Associatations of 30-day all-cause mortality in Clostridium difficile patients.

\begin{tabular}{|c|c|c|c|c|}
\hline Age (years) & $71(20)$ & $70(21)$ & $79(15)$ & $0.000 \mathrm{~b}$ \\
\hline Females [n (\%)] & $\begin{array}{l}201 \\
(61)\end{array}$ & $\begin{array}{l}166 \\
(83)\end{array}$ & $35(17)$ & \multirow{2}{*}{$0.317 a$} \\
\hline Males [n (\%)] & $\begin{array}{l}128 \\
(39)\end{array}$ & $\begin{array}{l}111 \\
(87)\end{array}$ & $17(13)$ & \\
\hline Duration of Admission (days) & $41(37)$ & - & - & - \\
\hline Total Known [n (\%)] & $\begin{array}{l}276 \\
(84)\end{array}$ & - & - & - \\
\hline Length of Infection (days) & $19(18)$ & - & - & - \\
\hline Total Known [n (\%)] & $\begin{array}{l}214 \\
(65)\end{array}$ & - & - & - \\
\hline Place of Acquisition & - & - & - & - \\
\hline Total Known [n (\%)] & $\begin{array}{l}194 \\
(59)\end{array}$ & $\begin{array}{l}160 \\
(64)\end{array}$ & $34(62)$ & - \\
\hline Hospital [n (\%)] & $\begin{array}{l}187 \\
(96)\end{array}$ & $\begin{array}{l}154 \\
(96)\end{array}$ & $33(97)$ & $0.975 a$ \\
\hline Community [n (\%)] & $7(4)$ & $7(4)$ & $1(3)$ & $0.713 a$ \\
\hline Speciality Breakdown: & - & - & - & - \\
\hline Total Medical [n (\%)] & $\begin{array}{l}169 \\
(90)\end{array}$ & $\begin{array}{l}141 \\
(88)\end{array}$ & $28(82)$ & $0.809 a$ \\
\hline Total Surgical [n (\%)] & $18(10)$ & $13(8)$ & 5 & $0.283 a$ \\
\hline General Med. [n (\%)] & $38(20)$ & $30(19)$ & 8 & $0.606 a$ \\
\hline Geriatrics [n (\%)] & $47(25)$ & $35(22)$ & 12 & $0.211 a$ \\
\hline Oncology [n (\%)] & $10(5)$ & $8(5)$ & 2 & $0.841 a$ \\
\hline Nephrology [n (\%)] & $11(6)$ & $9(6)$ & 2 & $0.956 a$ \\
\hline Other $[\mathrm{n}(\%)]$ & $63(34)$ & $59(37)$ & 4 & $0.029 a$ \\
\hline Renal disease [n (\%)] & $61(21)$ & $50(17)$ & $11(4)$ & $0.989 a$ \\
\hline Total Known (n) & $\begin{array}{l}296 \\
(90)\end{array}$ & - & - & - \\
\hline WBC (x109/L) & $\begin{array}{l}11.1 \\
(8.5)\end{array}$ & $\begin{array}{l}10.5 \\
(8.4)\end{array}$ & $15.6(8)$ & $0.010 \mathrm{~b}$ \\
\hline Total Known [n (\%)] & $\begin{array}{l}184 \\
(56)\end{array}$ & - & - & - \\
\hline Creatinine $(\mu \mathrm{mol} / \mathrm{L})$ & $\begin{array}{l}129 \\
(119)\end{array}$ & $\begin{array}{l}120 \\
(116)\end{array}$ & $\begin{array}{l}195 \\
(120)\end{array}$ & $0.015 b$ \\
\hline Total Known [n (\%)] & $\begin{array}{l}184 \\
(56)\end{array}$ & - & - & - \\
\hline Albumin (g/L) & $\begin{array}{l}24.4 \\
(6.9)\end{array}$ & $25(6.8)$ & $\begin{array}{l}19.3 \\
(4.9)\end{array}$ & $0.000 \mathrm{~b}$ \\
\hline
\end{tabular}

\begin{tabular}{|l|l|l|l|l|l|}
\hline \multicolumn{2}{|l|}{ Total Known [n (\%)] } & $\begin{array}{l}180 \\
(55)\end{array}$ & - & - & - \\
\hline $\mathrm{Hb}(\mathrm{g} / \mathrm{dL})$ & $\begin{array}{l}10.9 \\
(1.8)\end{array}$ & $\begin{array}{l}10.9 \\
(1.8)\end{array}$ & $11(1.7)$ & $0.687 \mathrm{~b}$ \\
\hline \multicolumn{2}{|l|}{ Total Known [n (\%)] } & $\begin{array}{l}183 \\
(56)\end{array}$ & - & - & - \\
\hline \multicolumn{2}{|l|}{ Charlson Score } & $\begin{array}{l}4.9 \\
(2.1)\end{array}$ & $\begin{array}{l}4.9 \\
(2.2)\end{array}$ & $\begin{array}{l}5.3 \\
(1.8)\end{array}$ & $0.165 \mathrm{~b}$ \\
\hline $\mathrm{T}$ & Total Known [n (\%)] & $\begin{array}{l}183 \\
(56)\end{array}$ & - & - & - \\
\hline
\end{tabular}

Continuous variables are reported as means with standard deviations in parentheses. Binary or categorical variables are reported as absolute number and percentage (with total known number of observed values as the denominator). P-value for difference between survivors and nonsurvivors was not calculated for duration of admission or length of infection as for nonsurvivors this would have been biased by the 30-day definition of mortality. $\mathrm{Hb}$ haemoglobin; WBC, White blood cell count aP-value generated using Pearson's $\mathrm{X} 2$-test. bP-value generated using two-tailed t-test

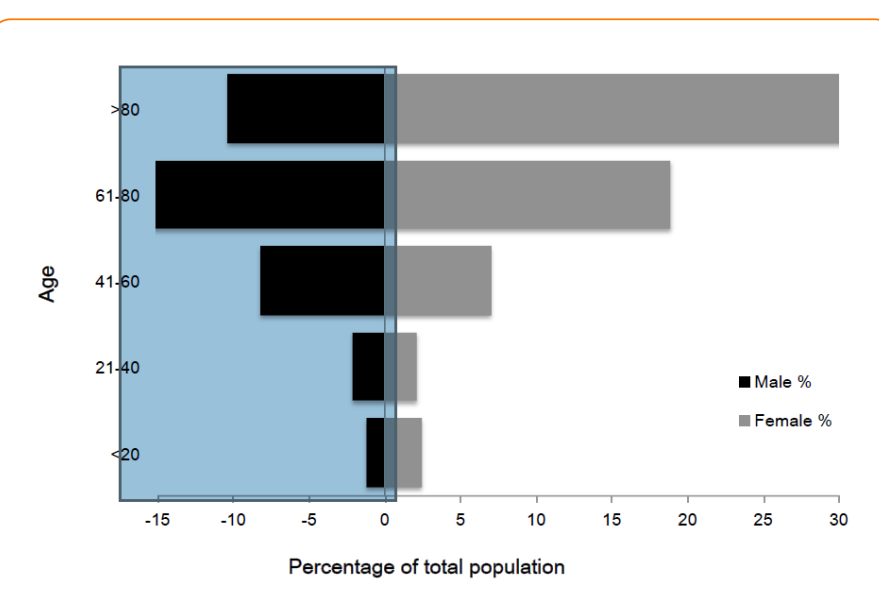

Figure 1: Clostridium difficile patient population distribution by age and sex.

\section{Discussion}

The demographics of the patients included in this study are similar to previously published work [18]. In line with the majority of studies over the past thirty years, advancing age is shown to be a major risk factor for both the incidence and mortality rate of CDAD with two thirds of patients in the study older than 70 years of age. In addition, the female:male ratio of $3: 2$ is similar to other study groups [28] although there appears to be no widely accepted reason for this, particularly as the mean age between the two sexes was not statistically different.

Consistent with previous research evaluating hospital databases, the vast majority of the individuals included in this study developed CDAD whilst in hospital. One study assessing community based CDAD suggested that community infections tend to affect younger, female patients with a decreased disease severity [29] With up to one third of infections. potentially developing outside of the hospital setting, it is likely that the reported CDAD incidence of around 1 per 1000 inpatient episodes [30] may underestimate the burden of CDAD on society as a whole. 
Around half of diagnoses were made on patients residing on medical wards with around 1 in 10 involving surgical patients. It has been reported that surgical patients developing CDAD may be significantly younger than their medical counterparts [31] however we were not able to demonstrate a significant demographic difference between the specialities.

All blood tests included within the study were taken within 3 days of diagnosis of CDAD. Whilst there is still an incomplete understanding of blood marker trends during CDAD, it has been shown that investigations, particularly WBC and albumin are most sensitive within the first 72 hours of onset of symptoms [32].

This study demonstrates that, when assessed together, the most reliable risk factors for increased mortality with CDAD are older age, higher white cell count, higher creatinine and lower albumin. These results are consistent with the findings of a systematic review evaluating previous studies [23] and further validates the usage of these factors in a predictive scoring system. The degree of co-morbidity, calculated using the Charlson index, showed a degree of positive prediction but not to adequate statistical significance and should therefore be used with care when predicting CDAD outcome. Haemoglobin and presence of renal disease showed no significant correlation with mortality and therefore appear to play no role in prediction of outcome.

As a number of the highlighted risk factors potentially influence one another, such as renal disease and haemoglobin, logistic regression analysis of mortality was performed to determine the independence of each risk factor. Only, albumin reached statistical significance using this method, although WBC achieved borderline significance. Most research investigating CDAD severity predictors have traditionally not compared univariate with multivariate analysis to eliminate confounding factors, with one systematic review identifying significant heterogeneity between studies [33]. These results confirm the importance of albumin and white cell count in any risk prediction model and support the findings of Miller et al. [20] who performed regression calculations on six parameters and again found WBC and albumin to be positive predictors of mortality. The use of small studies, poorly recorded data and reliance on univariate analysis has been criticised by systematic review, as a potential cause for heterogeneity in risk factors for mortality in CDAD [23]. The data presented further clarifies the need for larger scale prospective multivariate analysis in defining a clinically relevant scoring system for severity in CDAD.

Length of infection from initial diagnosis was influenced by both increased age and a higher white cell count. Low haemoglobin and the presence of renal disease showed a tendency towards increased duration of admission although not to statistical significance whilst albumin appeared to play no role. This may in part be explained by albumin being a significant predictor of early mortality thus shortening average in-patient stay. Previous research has suggested that medical co-morbidity as much as disease process results in a longer duration of admission and therefore increased healthcare cost [34]. however we were not able to show any correlation between the Charlson Index and LOI..
Certain studies have set cut-off values when assessing markers for high risk CDAD, for example "WBC $>15 \times 10 /$ I", or "serum albumin <25 g/l" [28]. Furthermore, the ATLAS score uses degree of leucocytosis and hypoalbuminaemia to define points in a CDAD severity scoring system. The authors recognise the importance of defining values in order to assess CDAD severity however to infer these cut-offs through retrospective analysis of data would introduce methodological bias. The authors would suggest cut-offs be defined in further prospective analyses, in order to facilitate risk stratification into mild, intermediate and fulminant CDAD.

A common problem encountered when assessing risk factors for mortality due to CDAD is the difficulty in formally attributing death to the infective process rather than to an ongoing comorbidity. By utilising the 30-day all-cause mortality rate, we have ensured a degree of standardisation with at least seventeen other papers identified in a previous systematic review analysing CDAD risk factors. By applying a set 30-day cutoff, we were able to concentrate on the infective period whilst minimising the effect of long-term, chronic co-morbidities.

Another difficulty encountered was the accurate documentation of co-morbidity. The Charlson Index was chosen, again to ensure a degree of standardisation with previously published studies, however the Index is a measure of chronic disease rather than an assessment of acute physiology. Although there was a trend towards mortality with a raised Charlson Index during the $t$ testing $(p=0.16)$, the linear regression analysis $(p=0.42)$ suggests that the majority of any positive predictive value was due to the age of the patient, which is used in calculating the index, rather than the degree of comorbidity.

Other measures of co-morbidity have been utilised in previous studies. One such study assessing the mortality rate of CDAD infection within the intensive care setting [35] demonstrated a mortality rate of over $35 \%$, and found that, particularly in fulminant cases, mortality was closely linked to the degree of co-morbidity as defined by the APACHE scoring system [36]. It has not yet been demonstrated whether these findings can be transferred to less severe cases.

A recently proposed index, the ATLAS scoring system [20] lists five variables (age, antibiotic treatment, white cell count, albumin and renal function) as predictors of CDAD mortality. Whilst high correlation between the score and treatment outcome was noted, the authors note that the patient population may not be representative of CDAD infection as a whole as inclusion criteria barred all severe and fulminant cases from the study. Although our data is supportive of the criteria used in the ATLAS scoring system it does not seek to validate the specific values used in the score.

The cost of CDAD is difficult to evaluate as it comprises many factors. A study from the $\mathrm{US}_{37}$ estimated an additional inpatient stay of 3.6 days resulted in a $50 \%$ or $\$ 3500$ increase in costs whilst a UK study 38 suggested an extra cost of $£ 4000$ per infection. In each of these studies the calculated extra cost resulted from prolonged hospital stay with other consequences, such as possible ward closure, loss of bed days, or infection control measures not generally taken into account. Therefore 
the true cost of CDAD infection is likely to be significantly underestimated.

\section{Conclusion}

The aim of this study was to validate the positive predictors for mortality and increased length of infection for Clostridium Difficile. Our results demonstrated older age, higher WBC, higher serum creatinine and lower serum albumin to be useful predictors of CDAD whilst haemoglobin, and degree of comorbidity were shown to be non-predictive markers.

Our data strongly support the findings of a previous systematic review [23] which are, however, contradictory to many of the currently proposed systems including the guidance laid out by Public Health England [19,23,25]. We are therefore critical of many CDAD risk prediction models, which use parameters such as haemoglobin, renal disease and comorbidity scores, whilst often ignoring factors such as patient age, WBC, creatinine or albumin [23,35-38]. Furthermore, we would recommend caution regarding the current guidance by Public Health England for the risk stratification of patients, which includes abdominal signs and tenderness but excludes albumin and patient age. This study adds a degree of insight into the factors affecting length of admission from diagnosis, which is, as yet, an understudied area of CDAD.

It is anticipated that these results can help direct the medical community towards a consensus regarding a CDAD risk prediction model, which has until now been difficult to formulate. By using reduced albumin, high creatinine, old age and high WBC as risk markers for mortality, physicians can be guided towards the appropriate allocation of resources in CDAD patient care.

\section{Competing Interests}

The author's declare no financial or non-financial competing interests.

\section{Author's Contributions}

WWM, first author and responsible for data collection, data processing, and literature review; DC, literature review and guidance; GMT, data processing and statistics; EGK, initial data collection and guidance; VK, conception, manuscript preparation, overall project guidance.

\section{Acknowledgements}

We would like to thank the National Institute for Health Research (NIHR) Cambridge Bioresource Research Centre for, their financial support for data collection purposes.

\section{Funding}

National Institute for Health Research (NIHR) Cambridge Bioresource Research Centre.

\section{References}

1. Hall IC, O'Toole E (1935) Intestinal flora in new-born infants : with a description of a new pathogenic anaerobe, Bacillus difficilis. Am J Dis Child 49: 390-402

2. Smith LDS, King EO (1962) Occurrence of Clostridium Difficile infections of man. J Bacteriol 84: 65-67.

3. Oake N, Taljaard M, von Walraven C (2010) The effect of hospitalacquired Clostridium dificile infection on in-hospital mortality. Arch Intern Med 170: 1804-1810.

4. Sailhamer EA, Carson K, Chang Y (2009) Fulminant Clostridium difficile colitis: patterns of care and predictors of mortality. Arch Surg 144: 433-439.

5. Thibault A, Miller MA, Gaese C (1991) Risk factors for the development of Clostridium dificile-associated diarrhea during a hospital outbreak. Infect Control Hosp Epidemiol 12: 345-348.

6. Garey KW, Sethi S, Yadav Y, DuPoint HL (2008) Meta-analysis to assess risk factors for recurrent Clostridium dificile infection. J Hosp Infectl 70: 298-304.

7. Pepin J, Saheb N, Coulombe MA (2005) Emergence of fluoroquinolones as the predominant risk factor for Clostridium difficile - associated diarrhea: a cohort study during an epidemic in Quebec. Clin Infect Dis 41: 1254-1260.

8. Dancer SJ (2001) The problem with cephalosporins. J Anti mic Chem 48: 463-478.

9. Cohen SH, Gerding DN, Johnson S (2010) Clinical practice guidelines for Clostridium dificile infection in adults: 2010 update by the society for healthcare epidemiology of America (SHEA) and the infectious diseases society of America (IDSA). Infect Control Hosp Epidemiol 31: 431.

10. Debast SB, Bauer MP, Kuijper EJ (2014) European Society of Clinical Microbiology and Infectious Diseases : update of the treatment guidance document for Clostridium difficile infection. Clin Micro boil Infect 2: 20.

11. McFarland LV (2005) Alternative treatments for Clostridium difficile disease: what really works? J Med Microbiol 54: 101-111.

12. Rupnik M, Wilcox MH, Gerding DN (2009) Clostridium difficile infection: new developments in epidemiology and pathogenesis. Nat Rev Microbiol 7: 526-536.

13. Department of Health and Health Protection Agency (2008) Clostridium difficile infection: How to deal with the problem. Infect Control Hosp Epidemiol 213.

14. Shannon-Lowe J, Matheson NJ, Cooke FJ, Aliyu SH (2010) Prevention and medical management of Clostridium difficile infection. BMJ 340: 641-646.

15. Pepin J, Valiquette L, Alary M-E (2004) Clostridium difficileassociated diarrhea in a region of Quebec from 1991 to 2003: a changing pattern of disease severity. CMAJ 71: 466-472.

16. Fawley WN, Freeman J, Smith C (2008) Use of highly discriminatory fingerprinting to analyze clusters of Clostridium difficile infection cases due to epidemic ribotype 027 strains. J Clin Microbiol 46: 954-960.

17. Goorhuis A, Bakker D, Corver J (2008) Emergence of Clostridium difficile infection due to a new hypervirulent strain, polymerase chain reaction ribotype 078. Clin Infect Dis 47: 1162-1170.

18. Karas JA, Enoch DA, Aliyu SH (2010) A review of mortality due to Clostridium difficile infection. J Infect 61: 1-8. 
19. Public Health England (2013) Updated guidance on the management and treatment of Clostridium difficile infection. $\mathrm{N}$ Engl J Med 6: 197-205.

20. Miller MA, Louie T, Mullane K (2013) Derivation and validation of a simple clinical bedside score (ATLAS) for Clostridium difficile infection which predicts response to therapy. BMC Infect Dis 13: 148.

21. Lowy I, Molrine DC, Leav BA (2010) Treatment with monoclonal antibodies against Clostridium difficile toxins. N Engl J Med 362: 197-205.

22. Aslam S, Hamill RJ, Musher DM (2005) Treatment of Clostridium difficile-associated disease: old therapies and new strategies. Lancet Infect Dis 5: 549-557.

23. Bloomfield MG, Sherwin JC, Gkrania-Klotsas E (2012) Risk factors for mortality in Clostridium difficile infection in the general hospital population: a systematic review. J Hosp Infect 82: 1-12.

24. Butt E, Foster JA, Keedwell E (2013) Derivation and validation of a simple, accurate and robust prediction rule for risk of mortality in patients with Clostridium difficile infection. BMC Infect Dis 13: 316.

25. Fujitani S, George WL, Murthy AR (2011) Comparison of clinical severity score indices for Clostridium difficile infection. Infect Control Hosp Epidemiol 32: 220-228.

26. Charlson ME, Pompei P, Ales KL, MacKenzie CR (1987) A new method of classifying prognostic comorbidity in longitudinal studies: development and validation. J Chronic Dis 40: 373-383.

27. Hall WH, Ramachandran R, Narayan S, Jani AB, Vijayakumar S (1999) An electronic application for rapidly calculating Charlson comorbidity score. BMC Cancer 4: 94.

28. Bloomfield MG, Carmichael AJ, Gkrania-Klotsas E (2013) Mortality in Clostridium difficile infection: a prospective analysis of risk predictors. Eur J Gastroenterol Hepatol 25: 700-705.
29. Khanna S, Pardi D, Aronson S (2012) The epidemiology of community-acquired Clostridium dificile infection: A populationbased study. Am J Gastroenterol 107: 89-95.

30. Zilberberg MD, Shorr AF, Kollef MH (2008) Increase in adult Clostridium difficile-related hospitalizations and case-fatality rate, United States 2000-2005. Emerg Infect Dis 14: 929-931.

31. Bhangu S, Bhangu A, Nightingale $P$ (2010) Mortality and risk stratification in patients with Clostridium difficile-associated diarrhoea. Colorectal Dis 12: 241-246.

32. Bhangu A, Czapran A, Bhangu S (2010) Optimum timing of blood tests for monitoring patients with Clostridium difficile-associated diarrhea. J Investig Med 58: 621-624.

33. Chakra C, Pepin J, Valiquette L (2011) Prediction tools for unfavourable outcomes in Clostridium difficile infection: a systematic review. Plos One 11: 165.

34. Kyne L, Merry C, O'Connell B (1999) Factors associated with prolonged symptoms and severe disease due to Clostridium difficile. Age Ageing 28: 107-113.

35. Kennealy C, Rosini J, Skrupky L (2007) Analysis of 30-day mortality for Clostridium dificile-associated disease in the ICU setting. Chest 132: 418-424.

36. Knaus WA, Draper EA, Wagner DP (1985) APACHE II: a severity of disease classification system. Crit Care Med 13: 818-829.

37. Kyne L, Hamel MB, Polavaram R (2002) Health care costs and mortality associated with nosocomial diarrhoea due to Clostridium difficile. Clin Infect Dis 34: 346-353.

38. Wilcox MH, Cunniffe JG, Trundle C (1996) Financial burden of hospital acquired Clostridium difficile infection. J Hosp Infect 34: 24-30. 